This item was submitted to Loughborough's Research Repository by the author.

Items in Figshare are protected by copyright, with all rights reserved, unless otherwise indicated.

\title{
DRS2020 Editorial: theme Co-creation
}

PLEASE CITE THE PUBLISHED VERSION

https://doi.org/10.21606/drs.2020.103

PUBLISHER

Design Research Society

VERSION

VoR (Version of Record)

\section{PUBLISHER STATEMENT}

This is an Open Access Article. It is published by Design Research Society under the Creative Commons Attribution-NonCommercial 4.0 International Licence (CC BY-NC). Full details of this licence are available at: https://creativecommons.org/licenses/by-nc/4.0/

\section{LICENCE}

CC BY-NC 4.0

\section{REPOSITORY RECORD}

Cain, Rebecca, and Stella Boess. 2020. "DRS2020 Editorial: Theme Co-creation”. Loughborough University. https://hdl.handle.net/2134/13072850.v1. 

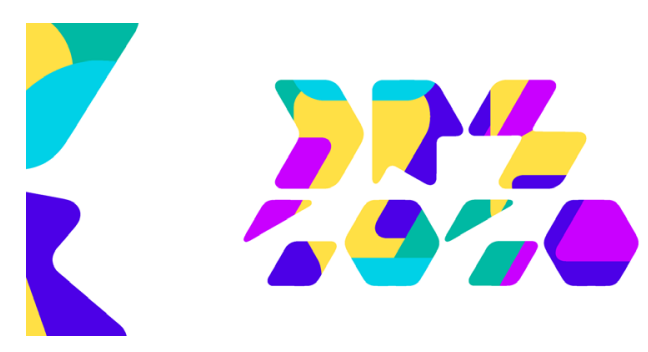

DRS2020

BRISBANE, 11-14 AUG

SYNERGY

\title{
Editorial: theme Co-creation
}

\author{
Rebecca CAIN, Stella BOESS \\ doi: https://doi.org/10.21606/drs.2020.103
}

Co-creation in all its forms - including participatory design, collaborative design, and codesign is continually an enduring theme at recent DRS Conferences, receiving a large number of submissions. Design researchers increasingly collaborate and co-create with other fields such as healthcare, engineering, political science, social sciences and with a wide variety of societal stakeholders and issues such as wellbeing, in addition to addressing developments such as networked, embedded and intelligent technologies. How can design research engage with people, other fields and support new interdisciplinary ways of working?

When submitting papers, authors were able to pick appropriate keywords for their papers which allowed the emergence of six sub-themes within the Co-Creation theme - Participation, Empowerment, Teamwork, Designers and Scientists, Social and Service Design and Mobility and Public Space. This is in addition to three DRS SIGs which also have themed Co-Creation sessions on Behaviour Change, Global Health and Health, Wellbeing and Happiness (SIGWELL).

The first two sub-themes, Participation and Empowerment are interlinked, with the Participation sub-theme exploring the more practical research mechanics of participatory design, whereas Empowerment focuses more on applications of participation in design. Within the Participation sub-theme, paper 246 presents a descriptive analytical framework that explores the materiality of artefacts used in the participatory design process. The framework aims to reduce barriers for participation in design activities and increase participant engagement. Papers 296 and 302 together look at the use of data and analysis within participatory design. Paper 296 develops methods that balance making data-rich video analysis accessible, while allowing novice analysts to make informed judgements. They use a video card game involving primary school teachers. Paper 302 suggests that the underpinning values of participatory design, those of empowerment and valuing lived experience create an opportunity to realise research data in a different way. The sub-theme of Empowerment drills down into particular applications of design techniques within collaborative settings. Design sprints aimed at co-designing healthcare services are examined in Paper 231, while in Paper 247, a collaborative co-design research project to tackle food 
poverty is described. Paper 367 presents a pilot study to resolve communication inequities in Qatar's construction industry.

Teamwork is an essential component of participation in design research, and the Teamwork sub-theme explores this through three papers which collectively explore technology, learning behaviour and remote collaboration. Paper 378 considers the social and technological implications of how remote collaborative-making mediated by technical tools might foster new ways of thinking and making through play and experimentation, affect social interactions and empower people to become producers and affect relationships between collaborators and the technologies in use through transparent processes. Paper 330 proposes that designers can improve their collaboration effectiveness by fostering team learning behaviours. Paper 398 is one of only a few papers in the proceedings to have re-positioned itself to reflect on its research in light of the COVID-19 pandemic. The paper proposes that in examining remote collaboration as a design problem, a new framework is needed to help teammates understand various differences such as how they build trust, exchange information and cope with creative abrasion. The paper highlights how COVID-19 has meant that design education and workplace activities have been thrust into new virtual spaces, amplifying some of the challenges associated by teamwork.

A popular domain in which to explore interdisciplinary and synergistic working is through the marriage of design and science. The Designers and Scientists sub-theme presents three papers all investigating this mode of synergy. Paper 126 addresses collaboration between design and science and explores how designers generate ideas from laboratories and how scientists perceive these ideas. Paper 154 explores through an applied example how narrative thinking helps to understand, communicate and disseminate information naturally and flexibly and Paper 182 looks at the commercialisation of scientific research in universities and explores practical tools to bridge the gap between research and the market. It proposes a multi-disciplinary workshop structure with the inclusion of designers and scientists working together.

The Co-Creation theme concludes with three applied papers within the Social and Service Design sub-theme. Within the context of service co-creation, the three papers together present three different international applications of social and service design. In paper 173, holistic service design thinking was used to optimize the services of a public animal shelter in Taiwan using co-creation, highlighting the complexity of stakeholder relationships. Paper 259 describes how a real-world social design project in New Zealand energized design students to engage in their studio activities in a learning process that was informal, generative and supportive. Finally, paper 273 looks at the crisis of social problems in Nigeria and describes a collaboration between three universities on a project to intervene in the crisis. Using a codesign methodology, the project aimed to improve educational materials and strategies in schools.

The final sub-theme within Co-Creation is Mobility and Public Space. A number of related papers were accepted, illustrating this as a ripe area for research within the context of co- 
creation. Paper 308 proposes a Virtual Reality Platform to discover subjective preferences on public waiting rooms, Paper 364 explores young people's experiences of journeys to work to create a scenario approach designed to bring together transport designers and end users' views, and Paper 396 prioritises fitness runners' experiences and preferences in running outdoors in China, for example by focusing on their music preferences to fit experiential and environmental conditions, and proposes an initial framework combining interactive convenience, environmental factors and running state.

Overall, the papers within the Co-Creation theme demonstrate the extensive scope of the theme. There are many examples of inspiring applications of co-creation within an international context, while at the same time, the theoretical aspects of co-creation as an umbrella of different methods and processes is also evident. In a similar vein to the Impact theme, central to the theme of co-creation is the idea of collaboration and teamwork. As paper 398 in this theme highlighted, the challenges presented by COVID-19 in terms of collaboration and teamwork will no doubt inform and inspire design research into cocreation for many years to come. In this respect, synergistic ways of working creatively in a collaborative way with stakeholders and people will be a fertile area for future research. 